\title{
Numerical Comparison of a Combined Hydrothermal Carbonization and Anaerobic Digestion System with Direct Combustion of Biomass for Power Production
}

\author{
Mohammad Heidari ${ }^{1}$, Shakirudeen Salaudeen ${ }^{1}{ }^{\mathbb{D}}$, Omid Norouzi $^{1}$, Bishnu Acharya ${ }^{2}$ and \\ Animesh Dutta $1, *$ (D) \\ 1 School of Engineering, University of Guelph, Guelph, ON N1G 2W1, Canada; mheidari@uoguelph.ca (M.H.); \\ ssalaude@uoguelph.ca (S.S.); norouzio@uoguelph.ca (O.N.) \\ 2 School of Sustainable Design Engineering, University of Prince Edward Island, Charlottetown, \\ PE C1A 4P3, Canada; bacharya@upei.ca \\ * Correspondence: adutta@uoguelph.ca; Tel.: +1-519-824-4120 (ext. 52441)
}

Received: 13 November 2019; Accepted: 21 December 2019; Published: 1 January 2020

\begin{abstract}
Two of the methods for converting biomass to fuel are hydrothermal carbonization (HTC) and anaerobic digestion (AD). This study is aimed at designing and analyzing two scenarios for bioenergy production from undervalued biomass (sawdust). In one of the scenarios (direct combustion or DC), raw biomass is burned in a combustor to provide the heat that is required by the Rankine cycle to generate electricity. In the other scenario (HTC-AD), the raw biomass first undergoes HTC treatment. While the solid product (hydrochar) is used to produce power by a Rankine cycle, the liquid by-product undergoes an AD process. This results in fuel gas production and it can be used in a Brayton cycle to generate more power. Energy and mass balance analysis of both scenarios were developed for each unit process by using Engineering Equation Solver (EES). The required data were obtained experimentally or from the literature. The performances of the proposed systems were evaluated, and a sensitivity analysis was presented to help in finding the best operational conditions.
\end{abstract}

Keywords: hydrothermal carbonization; anaerobic digestion; bioenergy; direct combustion; power cycles; Engineering Equation Solver

\section{Introduction}

The rising demand for energy around the globe is leading to economic and environmental problems, as the current supply of energy is highly reliant on fossil fuels. New sources and systems of energy should be explored to reduce the dependence on scarce, expensive, and polluting fossil fuels. Biomass is accounted as one of the most abundant and available wastes, and it is a carbon carrier that can be used to produce bio-energy [1]. However, raw biomass is less attractive due to the existence of several drawbacks, such as high moisture content, low energy density, hydrophilicity, and high alkali content which makes transportation, storage, and usage of the biomass difficult [2]. Thermochemical and biochemical conversion technologies, such as torrefaction, pyrolysis, gasification, hydrothermal carbonization (HTC), and anaerobic digestion (AD) are used to tackle these barriers. Among these technologies, anaerobic digestion and hydrothermal carbonization are highly taken into account, due to their relatively lower temperatures and their ability to deal with high moisture content biomass [3].

HTC is a wet process that involves the reaction of biomass with hot $\left(180-260^{\circ} \mathrm{C}\right)$, pressurized (2-6 MPa) liquid water. During this process, numerous chemical reactions take place, including hydrolysis, condensation, and decarboxylation [4]. The produced char is called hydrochar to distinguish it from biochar, which is obtained from non-hydrothermal processes, such as torrefaction and pyrolysis [3]. The inputs to this system usually include raw biomass, water, and energy (heat) and 
the outputs are hydrochar, a gas stream and a liquid stream (process water) [5]. AD is a collection of processes, by which microorganisms break down biodegradable material in the absence of oxygen. The main product of AD is biogas, which consists of methane, carbon dioxide, and traces of other gases [6]. In addition to biogas, digestate is a by-product of AD that consists of left-over indigestible material and dead micro-organisms. Biomass can also directly combust to produce energy. Although thermochemical processes (like HTC), and biochemical processes (like AD), are highly noticed in the recent years, direct combustion (where the raw biomass is burnt in excess air to produce heat) is perhaps the simplest way to convert biomass to bioenergy [7-9]. Hence, the proposed systems to convert biomass to bioenergy should be compared with the direct combustion.

Research on biomass conversion has been extensively conducted in the lab scale; however, there is a sensible gap regarding the practical and industrial design and environmental assessments. The integration of the biomass treating processes can not only make the whole process more energy-efficient, but it can also further reduce the waste considerably based on the circular economy [4]. Reza et al. [10] used the digestate from an AD process operating at thermophilic conditions $\left(50-60{ }^{\circ} \mathrm{C}\right)$ as a feed for HTC. The energy recovery of this combination was $20 \%$ higher than energy recovery from HTC and $60 \%$ higher than the one for AD. The AD-HTC process that was proposed by Reza et al. [10] can be reversed to HTC-AD [11], such that the biomass is firstly fed to the HTC process, where its alkali content dissolves in the process water (PW) and it can produce hydrochar with lower ash content that is more suitable for boilers [12]. It is worthy to mention that proper process condition should be considered to ensure that the ash content will reduce in HTC; otherwise, there is a possibility of increase in ash content in some cases [13]. In addition to the use of hydrochar for power generation, the process water can enter an existing AD system. The $\mathrm{pH}$ of the $\mathrm{PW}$ is in the range of 2.7-3.5 [14,15] and, hence, it can accelerate the hydrolysis step in AD. Ease of conversion in the AD system is expected, as hydrolysis is considered to be the limiting factor of AD systems [16].

This study is aimed at introducing two different scenarios for bioenergy production while using direct combustion for one scenario and a combination of hydrothermal carbonization and anaerobic digestion for the other one. Both scenarios integrate the power cycles and the biomass conversion processes with heat recovery and internal energy supply. The required data for HTC were obtained from lab-scale experiments. These data include hydrochar's mass yield, heating value, and elemental composition. Engineering Equation Solver (EES) developed the governing thermodynamic equations of the systems. The main goals of this study are to develop and perform numerical analysis on an integrated HTC-AD scenario for converting biomass to energy, and compare the performance of electricity production by the proposed method with direct combustion of the raw biomass.

\section{Materials and Methods}

Both systems that were analyzed in this study can work with a variety of biomass. For this study, sawdust has been considered as the feedstock, which is tiny pieces of wood that fall as powder from wood as it is cut by a saw [17]. Sawdust is one of the most abundant biomass sources, with more than five-million tonnes of sawdust surplus were available in Canada alone in 2004 [18].

Some of the main primary datasets were obtained by performing lab-scale experiments. The HTC experiments were conducted while using a Parr $600 \mathrm{~mL}$ series 4560 mini reactor (Parr Instrument Company, Moline, IL, USA) and approximately $20 \mathrm{~g}$ of sawdust was used for each experiment. For HTC, dry biomass to water mass ratio of 1:5 was used. After stirring the sawdust and water mixture in the reactor, it was sealed and pressurized by nitrogen gas to ensure that the pressure inside the reactor is always above saturation pressure of water. The reactor was then heated up to $220^{\circ} \mathrm{C}$ and kept at this temperature for $40 \mathrm{~min}$. The reactor was then immediately submerged into ice water until the temperature decreased to below $30^{\circ} \mathrm{C}$. The liquid-hydrochar mixture was removed from the reactor and then separated while using filter paper. The solid sample was placed inside a tin crucible and then left in a furnace overnight at $105^{\circ} \mathrm{C}$ to dry. 
A higher heating value (HHV) test was performed on the raw feed and solid products of HTC while using the IKA bomb calorimeter (IKAWorks, Wilmington, NC, USA). Moreover, the proximate analysis and ultimate analysis were performed on the obtained hydrochar and the raw sample. More details on the procedure of these characterization tests and the composition of the products can be found in Ref. [15].

In the HTC-AD scenario, HTC was scaled up and combined with Rankine, and Brayton cycles and anaerobic digestion process. Figure 1 shows the schematic of scenario 1. As is shown in Figure 1, biomass is mixed with hot pressurized water. It is worth mentioning that, unlike the lab-scale experiments, the HTC reactor is not pressurized with nitrogen gas, but is instead pressurized with the water that enters the reactor while using a high-pressure pump. Moreover, the required heat for HTC is provided by a heat exchanger that recovers the heat from the Rankine and Brayton cycles. The main product of HTC is wet hydrochar that is utilized in a Rankine cycle after getting dried in the drier. Table 1 is a stream table to help understand the conditions of each stream in the HTC-AD scenario. The liquid by-product of the HTC exchanges its heat with the water stream entering the HTC reactor and then enters into the AD system. A gas stream enriched in methane and hydrogen that enters the Brayton cycle to produce more power is the main output of this AD system. The gas turbine's exhaust is at high temperature $[19,20]$; hence, before releasing this hot stream to the atmosphere, its heat is transferred to the HTC reactor. If the gas turbine's exhaust heat is insufficient for the HTC process, excess heat is supplied from the lower stages of the steam turbine of the Rankine cycle. The power that is generated by the steam turbine is used wherever electricity was required (for the pumps and the compressor).

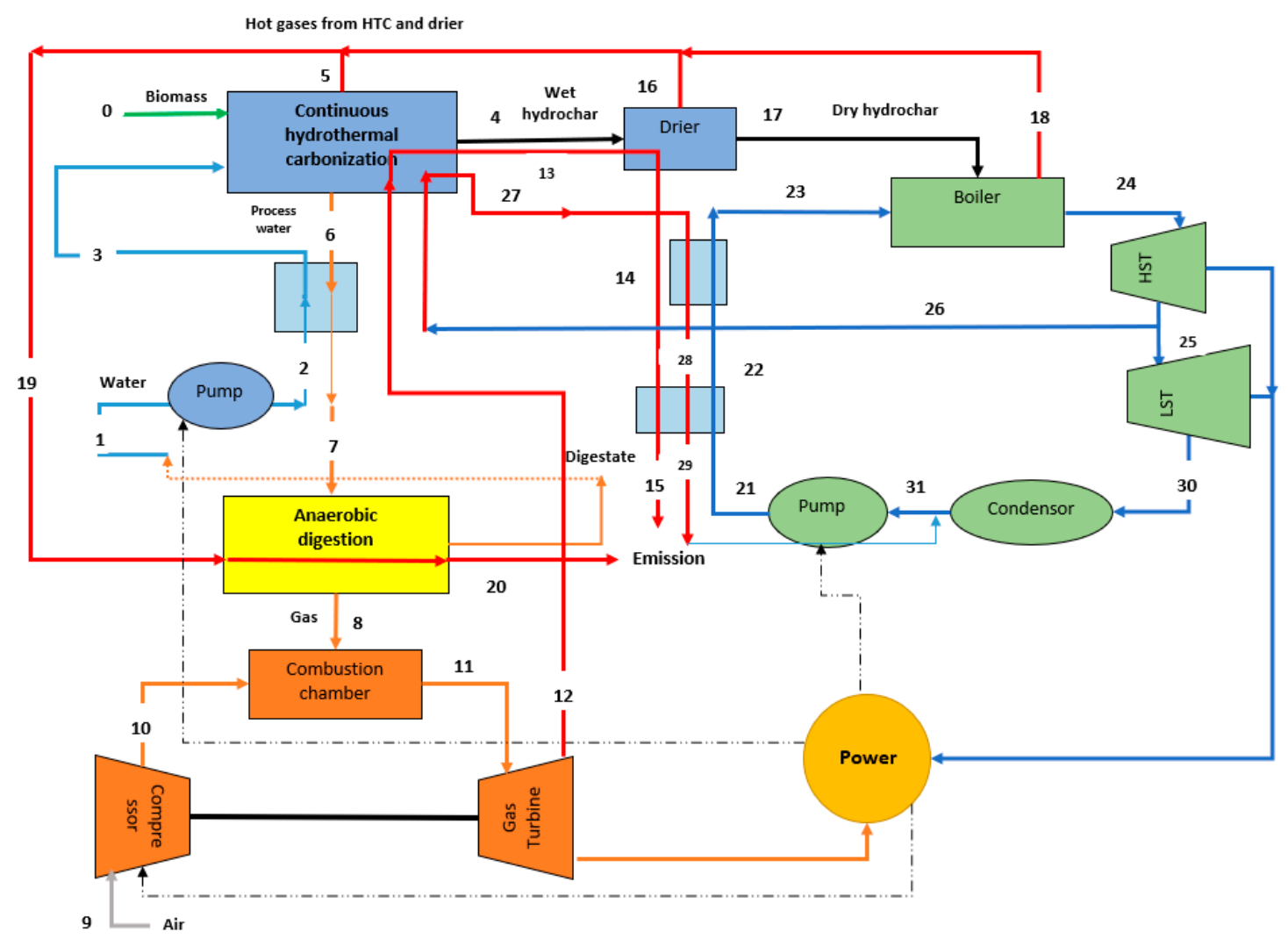

Figure 1. Schematic of the hydrothermal carbonization-anaerobic digestion (HTC-AD) scenario. 
Table 1. Stream table of the hydrothermal carbonization-anaerobic digestion (HTC-AD) scenario.

\begin{tabular}{|c|c|c|c|}
\hline State Number & Temperature $\left({ }^{\circ} \mathrm{C}\right)$ & Mass Flow Rate (g/s) & Other Properties \\
\hline 0 & 25 & 16 & $10 \%$ moisture content \\
\hline 1 & 25 & 75 & $p=101 \mathrm{kPa}$ \\
\hline 2 & 50 & 75 & $p=1800 \mathrm{kPa}$ \\
\hline 3 & 176.6 & 75 & $p=1800 \mathrm{kPa}$ \\
\hline 4 & 95 & 10.06 & Contains $0.7 \mathrm{~g} / \mathrm{s}$ of water \\
\hline 5 & 120 & 0.43 & Gaseous mixture (mainly $\mathrm{CO}_{2}$ ) \\
\hline 6 & 180 & 74.3 & Including $4.6 \mathrm{~g} / \mathrm{s}$ mass yield from biomass flow \\
\hline 7 & 60 & 74.3 & Mixture of water and acidic components \\
\hline 8 & 60 & 5.56 & Including $1.54 \mathrm{~g} \mathrm{CH} 4$, and the rest is $\mathrm{CO} 2$ \\
\hline 9 & 25 & 8.38 & $p=101 \mathrm{kPa}$ \\
\hline 10 & 473 & 8.38 & $p=1717 \mathrm{kPa}$ \\
\hline 11 & 1200 & 13.94 & $p=1717 \mathrm{kPa}$ \\
\hline 12 & 350 & 13.94 & Gaseous outlet of GT \\
\hline 13 & 230 & 13.94 & Gas \\
\hline 14 & 132.8 & 13.94 & Gas \\
\hline 15 & 50.53 & 13.94 & Gas emission \\
\hline 16 & 120 & 0.7 & Steam \\
\hline 17 & 50 & 9.36 & $\mathrm{HHV}=24,600[\mathrm{~kJ} / \mathrm{kg}]$ \\
\hline 18 & 120 & 86.92 & Gaseous mixture (mainly $\mathrm{CO}_{2}$ ) \\
\hline 19 & 120 & 88.05 & Gaseous mixtures to sustain $\mathrm{AD}$ process \\
\hline 20 & 25 & 88.05 & Gas emission \\
\hline 21 & 40.53 & 72.92 & $p=1800 \mathrm{kPa}$ \\
\hline 22 & 45 & 72.92 & Rankine process water \\
\hline 23 & 48 & 72.92 & Rankine process water \\
\hline 24 & 540 & 72.92 & Superheat steam \\
\hline 25 & 280 & 70.4 & $p=850 \mathrm{kPa}$ \\
\hline 26 & 280 & 2.52 & $p=850 \mathrm{kPa}$ \\
\hline 27 & 230 & 2.52 & Steam to heat up HTC \\
\hline 28 & 54.97 & 2.52 & Hot water \\
\hline 29 & 50.53 & 2.52 & Hot water \\
\hline 30 & 40 & 70.4 & Saturated steam \\
\hline 31 & 40 & 70.4 & Saturated water \\
\hline
\end{tabular}

As shown in Figure 2, the biomass is introduced to the drier as the first processing step in this scenario (direct combustion (DC)). Afterward, the dried biomass is utilized in a boiler to convert a water stream to steam, which can then produce the power after expansion in the turbine. Table 2 reports the stream table of the DC scenario. 


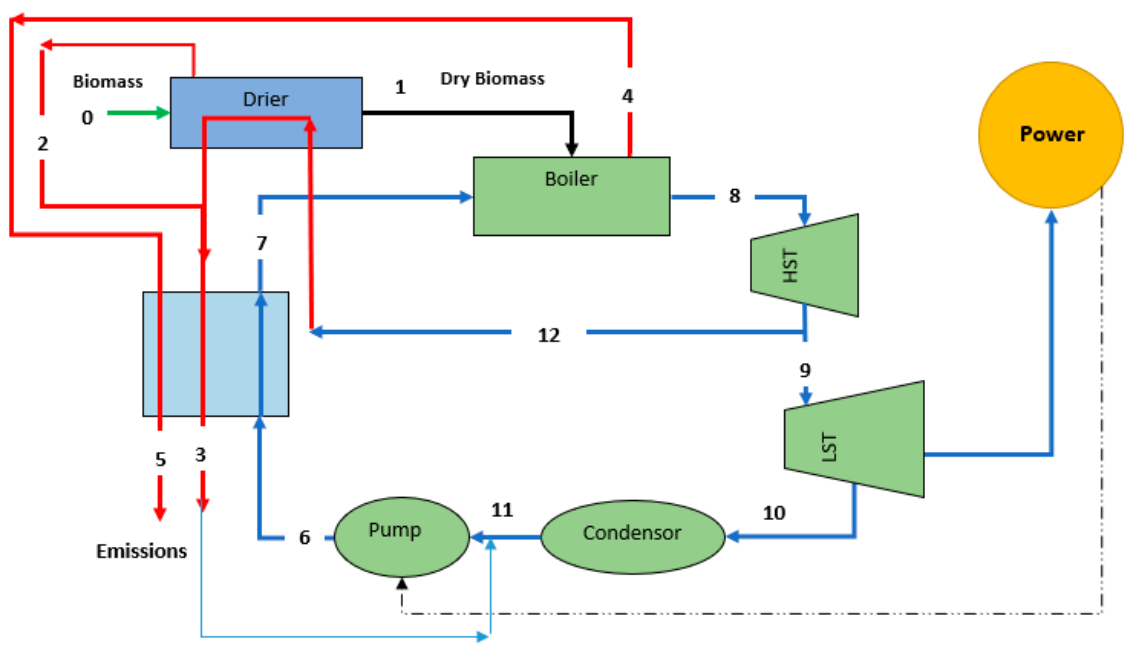

Figure 2. Schematic of the second direct combustion (DC) scenario.

Table 2. Stream table of the direct combustion (DC) scenario.

\begin{tabular}{cccc}
\hline State Number & Temperature $\left({ }^{\circ} \mathbf{C}\right)$ & Mass Flow Rate $(\mathrm{g} / \mathbf{s})$ & Other Properties \\
\hline 0 & 25 & 16 & $10 \%$ moisture content \\
\hline 1 & 50 & 14.40 & HHV $=17,800[\mathrm{~kJ} / \mathrm{kg}]$ \\
\hline 2 & 110 & 1.60 & Steam \\
\hline 3 & 50 & 4.38 & Water back to the cycle \\
\hline 4 & 110 & 141.55 & Gaseous mixture (mainly $\left.\mathrm{CO}_{2}\right)$ \\
\hline 5 & 50 & 141.55 & Gas emission \\
\hline 6 & 40.53 & 82.80 & Rankine process water \\
\hline 7 & 66.14 & 82.80 & Superheat steam \\
\hline 8 & 540 & 82.80 & Entering superheat steam to low \\
pressure GT
\end{tabular}

Several assumptions, such as the operational conditions of each equipment section, should be considered, as both systems incorporate several types of equipment. Moreover, some of the data was not obtained via experiments. Hence, this section clarifies the assumptions and data obtained from the literature.

It was assumed that HTC is scaled up to a continuous reactor and the flow rate of the biomass to this reactor is $0.016 \mathrm{~kg} / \mathrm{s}$. The same mass flow rate was considered for the DC scenario. The initial moisture content of the biomass was $10 \%$ and a 1:5 dry biomass to water weight ratio was considered for HTC.

The process water from HTC is acidic and it contains water, acetic acid, and a number of other organic acids [15]. According to Kambo et al. [14], these organic acids mainly contain acetic acid, 5-Hydroxyl Methyl Furfural (HMF), and levulinic acid. Table 3 reports the composition of the process water that was considered in this study. It is worthwhile to note that a more accurate and detailed research study on HTC should consider the presence of other organic compounds, such as glycolic acid or formic acid. In this research due to the high number of equations only three of the components were considered. 
Table 3. Composition of the bio-oil from HTC.

\begin{tabular}{ccc}
\hline Name & Chemical Formula & Weight $\%$ \\
\hline Acetic acid & $\mathrm{CH} 3 \mathrm{COOH}$ & 40 \\
\hline HMF & $\mathrm{C} 5 \mathrm{H} 8 \mathrm{O} 3$ & 40 \\
\hline levulinic acid & $\mathrm{C} 6 \mathrm{H} 6 \mathrm{O} 3$ & 20 \\
\hline
\end{tabular}

The chemical reactions of these acids in AD were considered based on Buswell and Muller [21] and they are as follows:

$$
\begin{gathered}
\mathrm{CH}_{3} \mathrm{COOH} \rightarrow \mathrm{CO}_{2}+\mathrm{CH}_{4} \\
\mathrm{C}_{5} \mathrm{H}_{8} \mathrm{O}_{3}+1.5 \mathrm{H}_{2} \mathrm{O} \rightarrow 2.25 \mathrm{CO}_{2}+2.75 \mathrm{CH}_{4} \\
\mathrm{C}_{6} \mathrm{H}_{6} \mathrm{O}_{3}+3 \mathrm{H}_{2} \mathrm{O} \rightarrow 3 \mathrm{CO}_{2}+3 \mathrm{CH}_{4}
\end{gathered}
$$

It should be noted that the presence of other elements, such as nitrogen (in other feedstocks such as algae), would result in nitrogen compunds in the bio-oil and bio-gas. Hence, the Equations (1)-(3) should be updated for other feedstocks. Moreover, the addition of materials that help to buffer $\mathrm{pH}$ changes and regulate the $\mathrm{pH}$ might be required, as the $\mathrm{pH}$ of the organic materials entering the $\mathrm{AD}$ is around 3, and most of the commercial AD systems work in a $\mathrm{pH}$ range of 6.7-7.8 [22].

The composition of the gas stream exiting the HTC reactor was considered to be all carbon dioxide due to its high abundance relative to other process gases, as discussed by Yan et al. [23]. The combustion of the biomass and hydrochar in the boilers, as well as the combustion of the obtained gases from $\mathrm{AD}$ in the combustion chamber, was considered with $150 \%$ of excess air.

It was assumed that the system operates at steady-state and steady flow conditions. Moreover, the HTC temperature was $220^{\circ} \mathrm{C}$, the AD system operates at $35^{\circ} \mathrm{C}$, the PW leaves the HTC reactor at $180{ }^{\circ} \mathrm{C}$, the air consists of $79 \%$ nitrogen, and $21 \%$ oxygen and the air, biogas, and combustion products are considered as ideal gases. Regarding the temperature of the PW, it should be noted that this temperature is highly dependent on the design of a continuous HTC system that can discharge the process water at that temperature. Given that, to date, there is no clear report regarding such a reactor, a sensitivity analysis will be performed to investigate the effects of lower temperatures of PW. The efficiencies for all exchangers, turbines, and compressors were considered as $80 \%$, whereas the efficiency was assumed as $70 \%$ for the pumps [24]. A temperature approach of $10{ }^{\circ} \mathrm{C}$ was considered for all heat exchangers. Moreover, the design is such that the boiler and the gas turbine exhaust supply the required heats for the drier and the HTC reactor, respectively. The compressor and pumps use a portion of the produced power. Table 4 reports other assumptions considered in the EES codes of the scenarios.

Table 4. Other assumptions of the integrated scenarios.

\begin{tabular}{cccc}
\hline Heat capacity of the biomass $(\mathrm{kJ} / \mathrm{kg} . \mathrm{K})$ & 1.5 & Ambient temperature $\left({ }^{\circ} \mathrm{C}\right)$ & 25 \\
\hline $\begin{array}{c}\text { Heat capacity of water at room } \\
\text { temperature }(\mathrm{kJ} / \mathrm{kg} . \mathrm{K})\end{array}$ & 4.18 & Ambient pressure $(\mathrm{kPa})$ & 101 \\
\hline $\begin{array}{c}\text { The heat of vaporization of water }(\mathrm{kJ} / \mathrm{kg}) \\
\text { Compressor exit pressure }(\mathrm{kPa})\end{array}$ & 2260 & $\begin{array}{c}\text { Maximum combustor } \\
\text { temperature }\left({ }^{\circ} \mathrm{C}\right)\end{array}$ & 900 \\
\hline Methane heating value $(\mathrm{MJ} / \mathrm{kg})$ & 55.51 & $\begin{array}{c}\text { The temperature of PW leaving } \\
\text { HTC reactor }\left({ }^{\circ} \mathrm{C}\right)\end{array}$ & 180 \\
\hline Flue gas temperature $\left({ }^{\circ} \mathrm{C}\right)[25]$ & 150 & $\begin{array}{c}\text { Exothermic heat of reaction in } \\
\text { HTC }(\mathrm{kJ} / \mathrm{kg})[26]\end{array}$ & 765 \\
\hline $\mathrm{ST}$ inlet temp. $\left({ }^{\circ} \mathrm{C}\right)$ & 530 & GT exhaust temp. $\left({ }^{\circ} \mathrm{C}\right)[27]$ & 350 \\
\hline
\end{tabular}




\section{Results}

\subsection{Experimental Results}

Table 5 reports the experimental results from characterization tests on the raw biomass and hydrochar obtained from HTC at $220^{\circ} \mathrm{C}$ for $40 \mathrm{~min}$.

Table 5. Experimental results from characterization on the biomass and hydrochar.

\begin{tabular}{|c|c|c|c|c|c|c|c|c|c|c|c|c|}
\hline Sample Name & \multicolumn{3}{|c|}{ Yields (\%) } & \multicolumn{5}{|c|}{ Ultimate Analysis (wt \%) } & \multicolumn{3}{|c|}{ Proximate Analysis (wt\%) } & $\begin{array}{c}\text { Calorimetry } \\
\text { HHV (MJ/kg) }\end{array}$ \\
\hline Raw & - & - & - & 49.22 & 6.10 & 0.01 & 0 & 44.57 & 0.10 & 17.80 & 82.10 & 17.8 \\
\hline Hydrochar & 65 & 32 & 3 & 63.51 & 5.33 & 0.02 & 0 & 31.12 & 0.02 & 31.24 & 68.74 & 24.6 \\
\hline
\end{tabular}

The empirical formula of the raw biomass and the hydrochar can be obtained as $\mathrm{C}_{1.47} \mathrm{H}_{2.23} \mathrm{O}$ and $\mathrm{C}_{2.72} \mathrm{H}_{2.74} \mathrm{O}$, respectively, based on the ultimate analysis that is reported in Table 5, and the molar number of the elements. These formulas were then used in the combustion equations in the boilers.

$$
\begin{aligned}
& \mathrm{C}_{2.72} \mathrm{H}_{2.74} \mathrm{O}+2.9\left(\mathrm{O}_{2}+3.76 \mathrm{~N}_{2}\right) \rightarrow 2.72 \mathrm{CO}_{2}+1.37 \mathrm{H}_{2} \mathrm{O}+10.9 \mathrm{~N}_{2} \\
& \mathrm{C}_{1.47} \mathrm{H}_{2.23} \mathrm{O}+1.52\left(\mathrm{O}_{2}+3.76 \mathrm{~N}_{2}\right) \rightarrow 1.47 \mathrm{CO}_{2}+1.11 \mathrm{H}_{2} \mathrm{O}+5.7 \mathrm{~N}_{2}
\end{aligned}
$$

It should be noted that the ash content is an important element to consider when it comes to energy production from biomass. The ash content of the feedstock in this study was negligible $(0.1 \%)$, but this may not be the case for other feedstocks. For instance, according to Phyllis database [28], the sawdust of different woods may contain up to $2 \%$ of ash content. In such situtations, more treatments, like de-ashing before the combustion or utilizing specific boilers that can handle the ash content of the feedstock, should be considered.

\subsection{Modeling Results}

The preliminary results of the scenarios that are given in Table 6 are based on the assumptions and the calculations discussed above. As can be seen in Table 6, the direct combustion of biomass with $10 \%$ moisture content shows a better relative performance. The total power that is produced by the DC scenario is $101 \mathrm{~kW}$, which is $5.21 \mathrm{~kW}$ higher than the HTC-AD scenario. In addition, the efficiency of the DC scenario is around $\%$ higher than that of the HTC-AD scenario.

Table 6. Composition of the bio-oil from HTC.

\begin{tabular}{ccc}
\hline Item & HTC-AD Scenario & DC Scenario \\
\hline Biomass flow rate $(\mathrm{g} / \mathrm{s})$ & 16 & 16 \\
\hline Total produced power $(\mathrm{kW})$ & 95.79 & 101 \\
\hline Efficiency $(\%)$ & 37.37 & 39.40 \\
\hline Power by the steam turbine $(\mathrm{kW})$ & 90.03 & 103.10 \\
\hline Power by the gas turbine $(\mathrm{kW})$ & 11.74 & - \\
\hline $\begin{array}{c}\text { Net power consumed by the HTC reactor }(\mathrm{kW}) \\
\text { (supplied from the boiler and GT exhaust) }\end{array}$ & 6.90 & - \\
\hline $\begin{array}{c}\text { The power produced by exothermic reactions }(\mathrm{kW}) \\
\text { Net energy consumed by the drier }(\mathrm{kW}) \text { (supplied } \\
\text { from the boiler) }\end{array}$ & 11.02 & 5.92 \\
\hline
\end{tabular}


It is worth reminding the reader here that these results do not consider the complexities of the integration in the HTC-AD scenario and the possible problems with slagging and fouling in the DC scenario due to the direct use of biomass without treatments. Moreover, it should be noted that the assumptions considered in obtaining the results that are reported in Table 5 had significant effects on the results. Out of the many assumptions listed above, the uncertainty that is associated with some parameters warrants further investigation. Hence, in the following sections, the effects of moisture content, HHV, and water in the HTC process on the total produced powers and efficiencies of both scenarios are investigated.

\subsection{Sensitivity Analysis}

\subsubsection{Biomass Moisture Content}

The moisture content of the biomass is one of the key parameters for selecting a technology that deals with biomass to bioenergy conversion. Figure $3 \mathrm{a}, \mathrm{b}$ show the effects of this parameter on both of the scenarios.
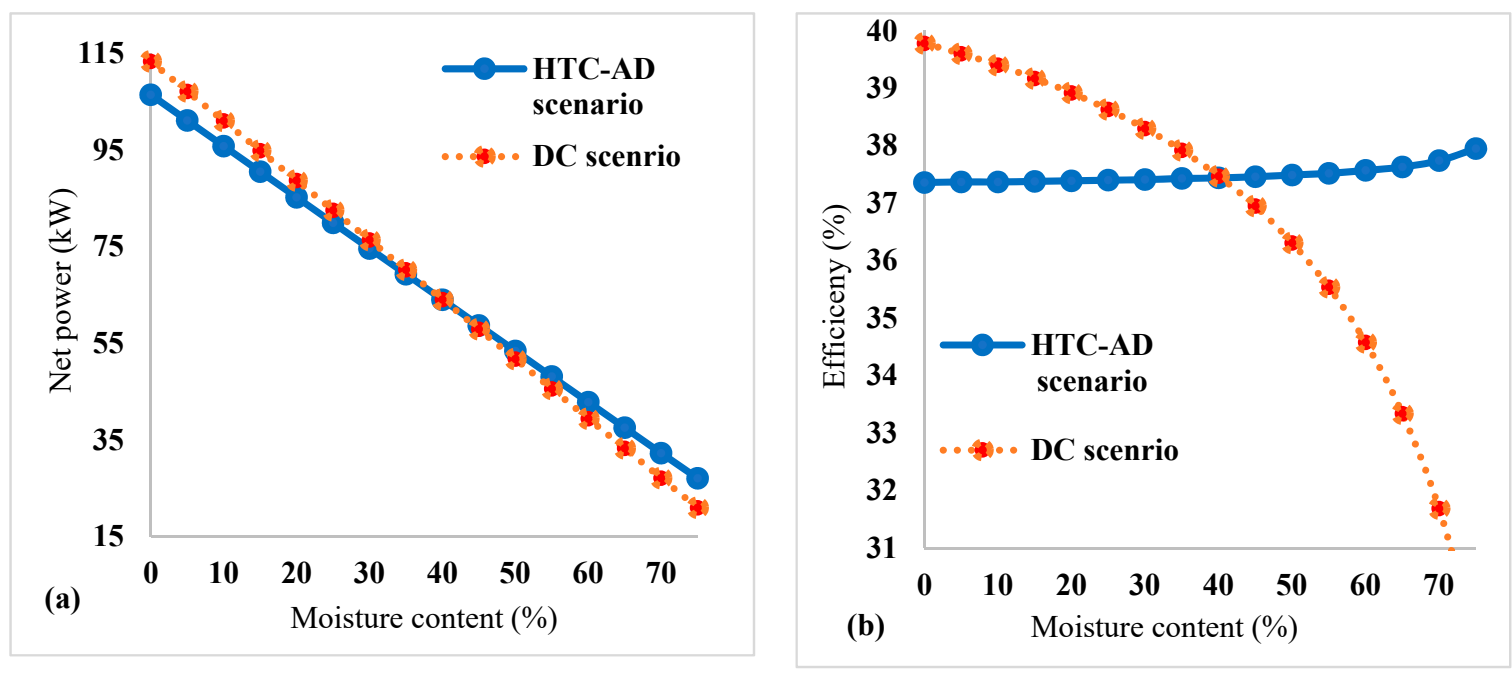

Figure 3. Effects of biomass moisture content on (a) net power, and (b) efficiency of each scenario.

Increasing the moisture content of the biomass feedstock decreased the total power that was produced by both scenarios. With an increase in the moisture content from 0 to $70 \%$, the power that was produced from the HTC-AD scenario dropped from $106.4 \mathrm{~kW}$ to $32.24 \mathrm{~kW}$, while, for the DC scenario, it was from $113.30 \mathrm{~kW}$ to $27.08 \mathrm{~kW}$. Regarding efficiency, the DC scenario shows a considerable decrease in the overall efficiency with an increase in the moisture content. However, for the HTC-AD scenario, the efficiency showed a slight increase with an increase in the moisture content. This interesting result shows that the main advantage of processes that use HTC for treating the biomass is when the moisture content is higher. The processes that involve an initial stage of drying exhibit a reduction in efficiency due to higher amounts of moisture, which is energy intensive to remove. The power consumption of the drier in the DC scenario increases from $5.91 \mathrm{~kW}$ to $22.39 \mathrm{~kW}$, when the moisture increases from $10 \%$ to $50 \%$. As shown in Figure 3, the HTC-AD scenario shows a better performance than the DC one when the moisture content of the biomass is over $40 \%$. 


\subsubsection{HHV of the Raw Biomass and Obtained Hydrochar}

Higher heating value (HHV) is one of the critical properties when it comes to the design and calculations of thermal conversion systems for biomass. HHV can be considered to be a specific property of each biomass, as its value is different from one biomass to another. The HHV of the hydrochar not only depends on the severity of the HTC process, but it is also highly dependent on the fiber structure and chemical composition of the biomass [29]. Figure $4 a, b$ show the effects of changes in the HHV of the raw biomass in the net power and efficiency, respectively. It is assumed that HHV of the hydrochar in the HTC-AD scenario is $6.8 \mathrm{MJ} / \mathrm{kg}$ higher than the corresponding HHV of the biomass-based on the results of the experiments (Table 5). It should also be noted that the moisture content is as its initial assumption (i.e., $10 \%$ ).
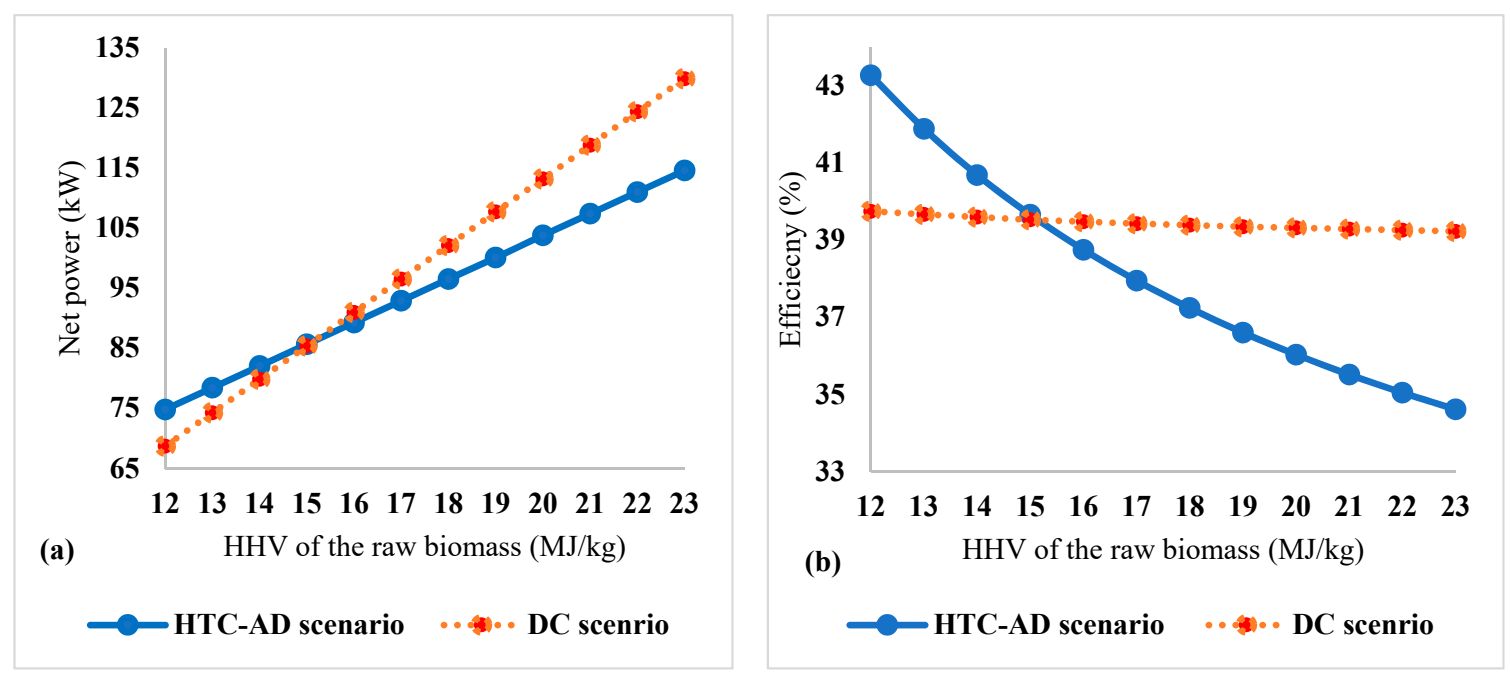

Figure 4. Effects of biomass higher heating value (HHV) on (a) net power and (b) efficiency of each scenario.

Figure 4a illustrates that, with an increase in the HHV of the biomass from 12 to $23 \mathrm{MJ} / \mathrm{kg}$, the net power that was produced by both scenarios increases. With HHVs lower than $15.5 \mathrm{MJ} / \mathrm{kg}$, the DC scenario produces less power and it has lower efficiency. This can be an indication that direct combustion can be a better option when the heating content of the biomass in its raw form is relatively high. For instance, when the lignin content of the biomass is higher [29].

\subsubsection{Water: Biomass Ratio and the Temperature and Composition of Process Water from HTC}

The main feature of HTC that makes it different from other thermochemical processes is it being performed under a water medium. All of the biomass particles in the HTC should be in contact with water; however, it is clear that the more water is used, the more energy is required for the process. Hence, the water to biomass ratio is one of the key parameters for the design of an HTC reactor. Figure 5 indicates the effect of water on biomass ratio on the performance of the HTC-AD scenario. As expected, the net power output and efficiency decrease with an increase in the water to biomass ratio. Therefore, it is suggested that the use of water should be minimized after it is ensured that the biomass is fully submerged in the water. 


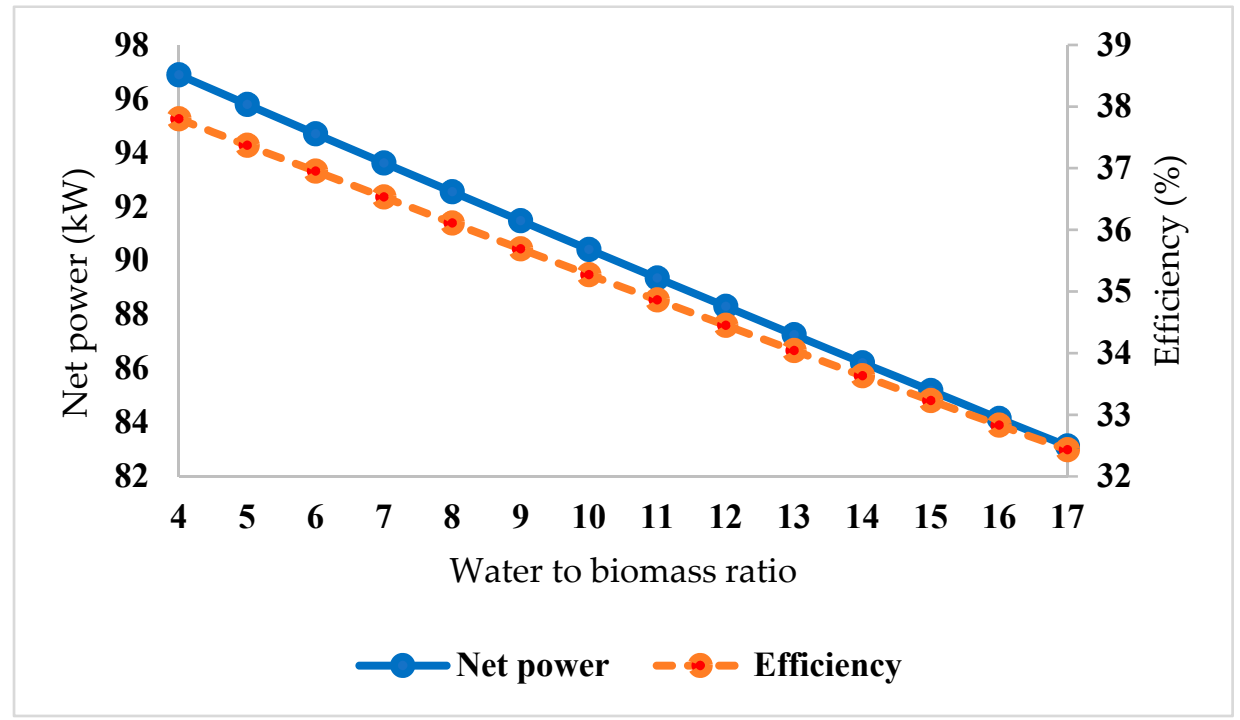

Figure 5. Effects water to biomass ratio on the performance of the HTC-AD scenario.

The other issue that can affect the HTC-AD scenario is the composition of the process of water entering the AD process. This is highly dependent on the type of biomass and HTC process condition. Figure 6 compares the performance of the HTC-AD scenario while considering that $100 \%$ of the obtained organic acids are one of the acetic acid, HMF, or levulinic acid. Figure 6 shows that the performance of the bioenergy systems improves if the composition of the PW contains more HMF or levulinic acid. The assumptions of $100 \%$ of these components are only from a statistical point of view to show the effects of each of the components clearly and cannot happen in real situation.

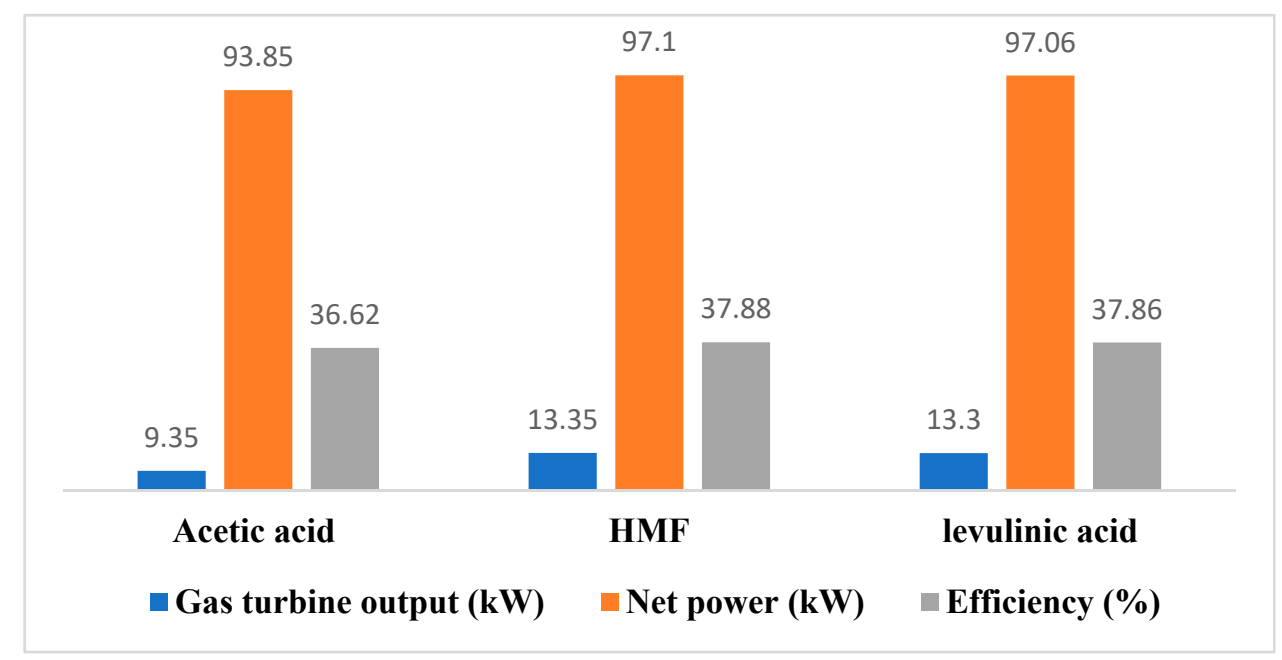

Figure 6. Effect of PW composition on the performance of the HTC-AD scenario.

In addition to the parameters that are discussed above, the PW temperature of the HTC process can play an important role in the reduction of energy usage by the HTC reactor and, consequently, the whole process. Figure 7 indicates the energy that was consumed by the HTC reactor, as well as the output power and efficiency of the HTC-AD scenario while varying the temperature of the PW. 


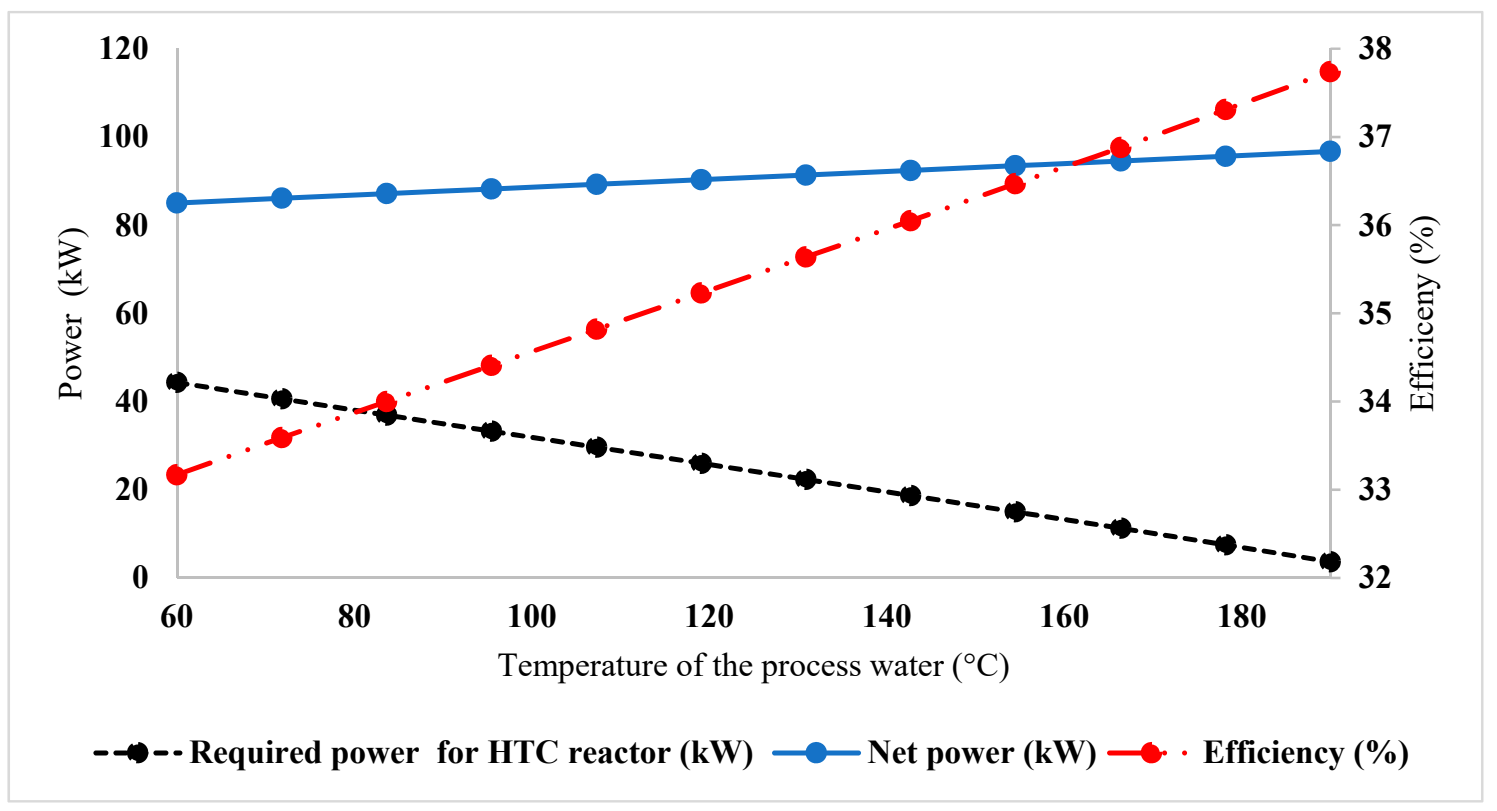

Figure 7. Effect of temperature of PW on the performance of the HTC reactor and overall scenario.

While considering a temperature of $220{ }^{\circ} \mathrm{C}$ for the HTC process, the ability of the reactor to discharge the process water to the heat exchanger in as high temperature as possible is crucial. The efficiency of the system can increase by around $5 \%$ with an increase in the temperature of the discharged $\mathrm{PW}$ from $40^{\circ} \mathrm{C}-190^{\circ} \mathrm{C}$. This again shows the importance of designing reactors that can recover the heat.

\section{Discussion}

This paper investigated two possible scenarios for producing power from biomass. The HTC-AD scenario integrated HTC and AD with power cycles, whereas the DC scenario only utilizes integrated direct combustion of the biomass with the Rankine cycle. It was shown that a $16 \mathrm{~g} / \mathrm{s}$ sawdust biomass stream with $10 \%$ moisture content can produce $95.79 \mathrm{~kW}$ power for the HTC-AD scenario, whereas the DC scenario can produce $101 \mathrm{~kW}$. While considering the complexity and potential capital costs of the HTC-AD scenario, the direct use of the biomass might seem like a better option for sawdust. However, it was shown that an increase in moisture content makes the HTC-AD scenario superior in terms of efficiency and produced power. In an integrated system, several parameters can have significant impact on the objective parameters of the system. For instance, it was shown that the benefits of the HTC-AD scenario are more sensible when the initial HHV of the biomass is lower, water to biomass ratio is lower, the type of the biomass generates acids, like HMF in its liquid yield, and there is heat recovery from the HTC unit. Further environmental and economic investigations are required to complete this study.

Author Contributions: Conceptualization, M.H. and A.D.; methodology, M.H. and S.S.; software, M.H. and S.S.; validation, M.H. and O.N.; investigation, M.H. and B.A.; resources, A.D. and B.A.; writing-review and editing, M.H., S.S., and O.N.; supervision, A.D. and B.A.; project administration, A.D. and B.A.; funding acquisition, A.D. All authors have read and agreed to the published version of the manuscript.

Funding: This research was funded by Natural Sciences and Engineering Research Council of Canada, grant number 400495, Environment and Climate Change (MOECC), Best in Science program, Project \#053191, and Ontario Ministry of Agriculture, Food and Rural Affairs (OMAFRA), Project\#030333.

Conflicts of Interest: The authors declare no conflict of interest. The funders had no role in the design of the study; in the collection, analyses, or interpretation of data; in the writing of the manuscript, or in the decision to publish the results. 


\section{References}

1. Uslu, A.; Faaij, A.P.C.; Bergman, P.C.A. Pre-treatment technologies, and their effect on international bioenergy supply chain logistics. Techno-economic evaluation of torrefaction, fast pyrolysis and pelletisation. Energy 2008, 33, 1206-1223. [CrossRef]

2. Uddin, M.H.; Reza, M.T.; Lynam, J.G.; Coronella, C.J. Effects of Water Recycling in Hydrothermal Carbonization of Loblolly Pine. Environ. Prog. Sustain. Energy 2014, 33, 1309-1315. [CrossRef]

3. Kambo, H.S.; Dutta, A. A comparative review of biochar and hydrochar in terms of production, physico-chemical properties and applications. Renew. Sustain. Energy Rev. 2015, 45, 359-378. [CrossRef]

4. Heidari, M.; Dutta, A.; Acharya, B.; Mahmud, S. A review of the current knowledge and challenges of hydrothermal carbonization for biomass conversion. J. Energy Inst. 2018, 92, 1779-1799. [CrossRef]

5. Funke, A.; Ziegler, F. Hydrothermal carbonization of biomass: A summary and discussion of chemical mechanisms for process engineering. Biofuels Bioprod. Biorefining 2010, 4, 160-177. [CrossRef]

6. Pecchi, M.; Baratieri, M. Coupling anaerobic digestion with gasification, pyrolysis or hydrothermal carbonization: A review. Renew. Sustain. Energy Rev. 2019, 105, 462-475. [CrossRef]

7. Rahdar, M.H.; Nasiri, F.; Lee, B. A Review of Numerical Modeling and Experimental Analysis of Combustion in Moving Grate Biomass Combustors. Energy Fuels 2019, 33, 9367-9402. [CrossRef]

8. Cherubini, F.; Peters, G.P.; Berntsen, T.; Strømman, A.H.; Hertwich, E. $\mathrm{CO}_{2}$ emissions from biomass combustion for bioenergy: Atmospheric decay and contribution to global warming. GCB Bioenergy 2011, 3, 413-426. [CrossRef]

9. Heidari, M.; Garnaik, P.P.; Dutta, A. The Valorization of Plastic Via Thermal Means: Industrial Scale Combustion Methods. In Plastics to Energy; William Andrew Publishing: Norwich, NY, USA, 2019; pp. 295-312.

10. Reza, M.T.; Werner, M.; Pohl, M.; Mumme, J. Evaluation of integrated anaerobic digestion and hydrothermal carbonization for bioenergy production. J. Vis. Exp. 2014, 88, e51734. [CrossRef]

11. Aragón-briceño, C.; Ross, A.B.; Camargo-Valero, M.A. Evaluation and comparison of product yields and bio-methane potential in sewage digestate following hydrothermal treatment. Appl. Energy 2017, 208, 1357-1369. [CrossRef]

12. Zhang, B.; Heidari, M.; Regmi, B.; Salaudeen, S.; Arku, P.; Thimmannagari, M.; Dutta, A. Hydrothermal Carbonization of Fruit Wastes: A Promising Technique for Generating Hydrochar. Energies 2018, 11, 2022. [CrossRef]

13. Iñiguez, M.E.; Conesa, J.A.; Fullana, A. Hydrothermal carbonization (HTC) of marine plastic debris. Fuel 2019, 257, 116033. [CrossRef]

14. Kambo, H.S.; Minaret, J.; Dutta, A. Process Water from the Hydrothermal Carbonization of Biomass: A Waste or a Valuable Product? Waste Biomass Valorization 2017, 9, 1181-1189. [CrossRef]

15. Heidari, M.; Salaudeen, S.; Dutta, A.; Acharya, B. Effects of Process Water Recycling and Particle Sizes on Hydrothermal Carbonization of Biomass. Energy Fuels 2018, 32, 11576-11586. [CrossRef]

16. Neves, L.; Oliveira, R.; Alves, M.M. Anaerobic co-digestion of coffee waste and sewage sludge. Waste Manag. 2006, 26, 176-181. [CrossRef]

17. Rominiyi, O.L.; Adaramola, B.A.; Ikumapayi, O.M.; Oginni, O.T.; Akinola, S.A. Potential Utilization of Sawdust in Energy, Manufacturing and Agricultural Industry; Waste to Wealth. World J. Eng. Technol. 2017, 05, 526-539. [CrossRef]

18. Bradley, D. Estimated Production, Consumption and Surplus Mill Wood Residue in Canada-2004: A National Report; BW McCloy \& Associates Inc. and Climate Change Solutions for the Canadian Forest Service and the Forest Products Association of Canada: Ottawa, ON, Canada, 2005.

19. Heidari, M.; Ataei, A.; Rahdar, M.H. Development and analysis of two novel methods for power generation from flare gas. Appl. Therm. Eng. 2016, 104, 687-696. [CrossRef]

20. Heydari, M.; Abdollahi, M.A.; Ataei, A.; Rahdar, M.H. Technical and Economic Survey on Power Generation by Use of Flaring Purge Gas. In Proceedings of the International Conference on Chemical, Civil and Environmental Engineering (CCEE-2015), Istanbul, Turkey, 5-6 June 2015.

21. Buswell, A.; Muller, H. Mechanism of methane fermentation. Ind. Eng. Chem. 1952, 44, 550-552. [CrossRef]

22. Huiru, Z.; Yunjun, Y.; Liberti, F.; Pietro, B.; Fantozzi, F. Technical and economic feasibility analysis of an anaerobic digestion plant fed with canteen food waste. Energy Convers. Manag. 2019, 180, 938-948. [CrossRef] 
23. Yan, W.; Hastings, J.T.; Acharjee, T.C.; Coronella, C.J.; Vásquez, V.R. Mass and energy balances of wet torrefaction of lignocellulosic biomass. Energy Fuels 2010, 24, 4738-4742. [CrossRef]

24. Mansouri, M.; De, S.; Assadi, M.; Breuhaus, P. An EU initiative for future generation of IGCC power plants using hydrogen-rich syngas: Simulation results for the baseline configuration. Appl. Energy 2012, 99, 280-290. [CrossRef]

25. Xu, G.; Huang, S.; Yang, Y.; Wu, Y.; Zhang, K.; Xu, C. Techno-economic analysis and optimization of the heat recovery of utility boiler flue gas. Appl. Energy 2013, 112, 907-917. [CrossRef]

26. Stemann, J.; Ziegler, F. Assessment of the Energetic Efficiency of A Continuously Operating Plant for Hydrothermal Carbonisation of Biomass. In Proceedings of the World Renewable Energy Congress-Sweden, Linköping, Sweden, 8-13 May 2011; Linköping University Electronic Press: Linköping, Sweden, 2011; pp. $125-132$.

27. U.S. Department of Energy. Combined Heat and Power Technology Fact Sheet Series Micro Turbines; DOE: Washington, DC, USA, 2016. Available online: https://www.energy.gov/sites/prod/files/2016/09/f33/CHPMicroturbines_0.pdf (accessed on 14 December 2019).

28. Phyllis2. Database for the Physico-Chemical Composition of (Treated) Lignocellulosic Biomass, Micro- and Macroalgae, Various Feedstocks for Biogas Production and Biochar. Available online: https://phyllis.nl/ (accessed on 12 November 2019).

29. Heidari, M.; Norouzi, O.; Salaudeen, S.A.; Acharya, B.; Dutta, A. Prediction of hydrothermal carbonization with respect to the biomass components and severity factor. Energy Fuels 2019, 33, 9916-9924. [CrossRef]

(C) 2020 by the authors. Licensee MDPI, Basel, Switzerland. This article is an open access article distributed under the terms and conditions of the Creative Commons Attribution (CC BY) license (http://creativecommons.org/licenses/by/4.0/). 